\title{
CULTIVO DE Klebsiella oxytoca EM GLICEROL PARA A PRODUÇÃO DE 2,3-BUTANODIOL EM BIORREATOR DE BANCADA
}

\author{
T. ROMIO ${ }^{1}$, C. HARTMANN ${ }^{1}$, F. VIAPIANA ${ }^{1}$, L. MENEGHEL $^{1}$, S. CARRA ${ }^{1}$, A. P. TORRES ${ }^{2}$, \\ M. P. SOUSA ${ }^{2}$, L. L. BEAL ${ }^{3}$, E. MALVESSI ${ }^{1}$, M. M. da SILVEIRA ${ }^{1}$ \\ ${ }^{1}$ Universidade de Caxias do Sul, Laboratório de Bioprocessos, Caxias do Sul-RS \\ ${ }^{2}$ Petrobrás, Centro de Pesquisa e Desenvolvimento (CENPES), Rio de Janeiro-RJ \\ ${ }^{3}$ Universidade Caxias do Sul, Laboratório de Tecnologias Ambientais, Caxias do Sul-RS \\ E-mail para contato: tiagoromio@gmail.com
}

\begin{abstract}
RESUMO - Glicerol, resíduo da produção de biodiesel, pode ser utilizado como fonte de carbono em processos fermentativos para a produção de 2,3-butanodiol por diferentes microrganismos. Neste trabalho, o crescimento da bactéria anaeróbia facultativa Klebsiella oxytoca ATCC 8724 foi avaliado em meio mineral suplementado com 20, 40 ou $60 \mathrm{~g} / \mathrm{L}$ de glicerol, em biorreator de bancada com $4 \mathrm{~L}$ de volume útil, a $37^{\circ} \mathrm{C}, \mathrm{pH} \mathrm{5,5}$, fluxo de aeração de 1,5 L/min e frequência de agitadores de 600rpm. Valores semelhantes de máxima velocidade específica de crescimento, cerca de $0,8 \mathrm{~h}^{-1}$, foram obtidos com variação da concentração celular entre 5,5 e 7,4g/L. A conversão de substrato em células (Yx/s) foi decrescente nas concentrações avaliadas, 0,27g/g $(20 \mathrm{~g} / \mathrm{L})$ a 0,12g/g $(60 \mathrm{~g} / \mathrm{L})$. O mais alto rendimento em butanodiol, $60 \%$, foi obtido com a concentração mais elevada de glicerol, uma vez que, sob limitação de oxigênio dissolvido, o substrato presente no meio foi preferencialmente convertido em produto pela via fermentativa.
\end{abstract}

\section{INTRODUÇÃO}

Atualmente, tem aumentado o uso de biodiesel como combustível líquido oriundo de fontes renováveis. No processo de produção do biodiesel, são gerados cerca de $10 \%$ de glicerol que, em primeira instância, poderia ser considerado um problema ambiental devido à alta da produção estimada para os próximos anos. Entretanto, o glicerol tem sido utilizado como fonte de carbono em bioprocessos de obtenção de intermediários da indústria química, como 1,3propanodiol, 2,3-butanodiol, etanol, ácidos orgânicos e de hidrogênio (Amaral et al., 2009).

Entre estes produtos, o 2,3-butanodiol tem aplicações comerciais, como na síntese de 1,3butadieno, intermediário da borracha sintética, e de diacetil, empregado na indústria de alimentos. Outras aplicações estão relacionadas à substituição do etilenoglicol como anti-congelante, por apresentar ponto de congelamento de $-60^{\circ} \mathrm{C}$ (Converti e Perego, 2002) e no uso direto como combustível, haja vista seu calor de combustão, da ordem de $27 \mathrm{KJ} / \mathrm{g}$, comparável ao do etanol (29 KJ/g) (Flickinger, 1980).

Na produção de butanodiol, a partir de glicerol, são utilizadas bactérias anaeróbias facultativas pertencentes aos gêneros Enterobacter e Klebsiella (Amaral et al., 2009). No 
processo envolvendo Klebsiella oxytoca, prevêem-se duas etapas, a primeira, sob intensa aeração do meio, priorizando a produção de biomassa, e a segunda, sob limitação de oxigênio, favorecendo a formação do produto (Rossi et. al., 2013).

Este trabalho teve como objetivo avaliar o crescimento e a formação de 2,3-butanodiol e etanol por K. oxytoca ATCC 8724, em biorreator de bancada, em meio contendo diferentes concentrações de glicerol como única fonte de carbono.

\section{MATERIAIS E MÉTODOS}

\subsection{Microrganismo}

O microrganismo utilizado nos experimentos foi $K$. oxytoca ATCC 8724. A linhagem foi mantida em meio ágar nutriente, a $4^{\circ} \mathrm{C}$.

\subsection{Meio de cultivo e condições experimentais}

Os ensaios foram realizados no meio mineral de Pirt e Callow (1958) (meio PC), contendo, em (g/L): $\mathrm{MgSO}_{4} .7 \mathrm{H}_{2} \mathrm{O}, 0,3 ; \mathrm{CaCl}_{2} .6 \mathrm{H}_{2} \mathrm{O}, 0,09 ; \mathrm{FeSO}_{4} .7 \mathrm{H}_{2} \mathrm{O}, 0,023 ; \mathrm{ZnSO}_{4} .4 \mathrm{H}_{2} \mathrm{O}$, 0,0038; $\left(\mathrm{NH}_{4}\right)_{2} \mathrm{SO}_{4}, 7,2 ;\left(\mathrm{NH}_{4}\right)_{2} \mathrm{HPO}_{4}, 6,0$. A este meio foi acrescentado glicerol, nas concentrações de 20, 40 e $60 \mathrm{~g} / \mathrm{L}$, como única fonte de carbono.

A cultura foi previamente ativada em meio PC suplementado com $20 \mathrm{~g} / \mathrm{L}$ de glicerol, incubada a $37^{\circ} \mathrm{C}$, por $24 \mathrm{~h}$. Após, foram preparados os inóculos em frascos Erlenmeyer de 500 $\mathrm{mL}$, contendo $80 \mathrm{~mL}$ de meio com $20 \mathrm{~g} / \mathrm{L}$ de glicerol, com $\mathrm{pH}$ inicial ajustado para 6,5. Estes meios foram inoculados com $4 \mathrm{~mL}(5 \% \mathrm{v} / \mathrm{v})$ de suspensão bacteriana previamente ativada, mantidos a $37^{\circ} \mathrm{C}$, sob agitação recíproca de $300 \mathrm{rpm}$, em agitador de bancada (Certomat U, B. Braun Biotech, Sartorius).

Os cultivos foram realizados em biorreator de bancada New Brunswick, modelo BioFlo/Celligen115, com $4 \mathrm{~L}$ de meio, $10 \%$ (v/v) de inóculo, em batelada, sob frequência de

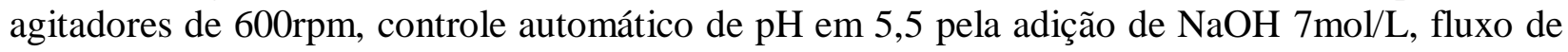
ar de $1,5 \mathrm{~L} / \mathrm{min}$ e temperatura de $37^{\circ} \mathrm{C}$. Amostras foram coletadas periodicamente para quantificação da biomassa, do consumo de substrato e de formação de produtos.

\subsection{Métodos analíticos}

A concentração de biomassa microbiana foi medida indiretamente a partir da absorbância de suspensões celulares, a 520nm, sendo convertidas em concentração - massa/volume - com uma curva de calibração. 


\section{9 a 22 de outubro de 2014 \\ Florianópolis/SC}

A concentração de glicerol foi determinada pelo método descrito por Carra (2012), definido para sorbitol e adaptado para glicerol.

Os principais produtos da fermentação, 2,3-butanodiol e etanol, foram determinados por cromatografia em fase líquida, em cromatógrafo Agilent Technology, modelo 9100, coluna Aminex HPX-87H $(300 \mathrm{~mm} \times 7,8 \mathrm{~mm}, 9 \mu \mathrm{m})$, volume de injeção de $50 \mu \mathrm{L}$, a $60^{\circ} \mathrm{C}$, vazão de $0,6 \mathrm{~mL} / \mathrm{min}$ e $\mathrm{H}_{2} \mathrm{SO}_{4}$ 0,0005M como fase móvel.

\section{RESULTADOS E DISCUSSÃO}

Com relação ao perfil de crescimento microbiano nos cultivos de $K$. oxytoca, o comportamento inicial foi semelhante, independentemente da concentração de glicerol testada. Em geral, foi observada uma fase de adaptação média de $3 \mathrm{~h}$, seguida de crescimento exponencial até aproximadamente 9h (Figura 1). Concentrações celulares superiores foram obtidas nos cultivos contendo 40 e $60 \mathrm{~g} / \mathrm{L}$ de glicerol, 7,4 e 6,8 g/L, respectivamente, em $24 \mathrm{~h}$ de processo (Figura 1B e 1C). O consumo de substrato foi maior a partir de $3 \mathrm{~h}$ de processo, em decorrência da alta atividade metabólica microbiana.

Em estudo anterior (Romio et al., 2013), com o emprego de glicerol como comparação à utilização de glicose como fontes de carbono, foi estimada maior biomassa em cultivos glicerol, assim como as superiores velocidades médias de crescimento e de consumo de glicerol. Este resultado corrobora os de Mendes (2011) e Silva et al. (2009), que destacam o fato do glicerol ser mais redutor que a glicose, gerando maior quantidade de NADH na sua degradação e que, ao regenerar o composto reduzido, geraria mais energia para o crescimento.

Como ilustrado na Figura 1, ocorreu uma queda acentuada do oxigênio dissolvido no meio durante a fase exponencial, que se tornou cada vez mais limitado devido à maior concentração celular. A partir dessa etapa, o glicerol passou a ser utilizado não mais apenas para a conversão em biomassa, mas também para a formação de produtos do catabolismo, 2,3butanodiol e etanol. Assim, com a menor geração de ATP em razão do aumento do consumo de substrato através do metabolismo fermentativo, houve uma forte redução da velocidade de crescimento. Quando há disponibilidade ilimitada de oxigênio, todo o glicerol presente no citosol é convertido a piruvato, seguindo-se a formação de acetil-CoA na mitocôndria que, por sua vez, entra no ciclo do ácido cítrico para a produção de energia para a célula. Nesse processo, há geração de acetato para a síntese de lipídios. Sob a limitação de oxigênio, o microrganismo não produz energia pela via aeróbia, desviando o piruvato para a via anaeróbia. Há produção de lactato e propanodiol no citosol e hidrogênio, etanol e 2,3-butanodiol, na mitocôndria, com o objetivo de reoxidar os NADH produzidos na conversão de glicerol em piruvato e ter energia metabólica para manutenção. Essas vias são independentes e o mais rentável para o microrganismo é reoxidar os NADH na via do 2,3-butanodiol, e menos rentável na via do etanol. A relação estequiométrica desses produtos é de $0,489 \mathrm{~g} / \mathrm{g}$ para o butanodiol (2 mol de glicerol gerando $2 \mathrm{~mol}$ de piruvato e, na sequência, $1 \mathrm{~mol}$ de 2,3-butanodiol) e 0,5 g/g para o etanol (1 
mol de glicerol gerando $1 \mathrm{~mol}$ de piruvato e, após, 1 mol de etanol) (Amaral et.al., 2009; Mendes, 2011).
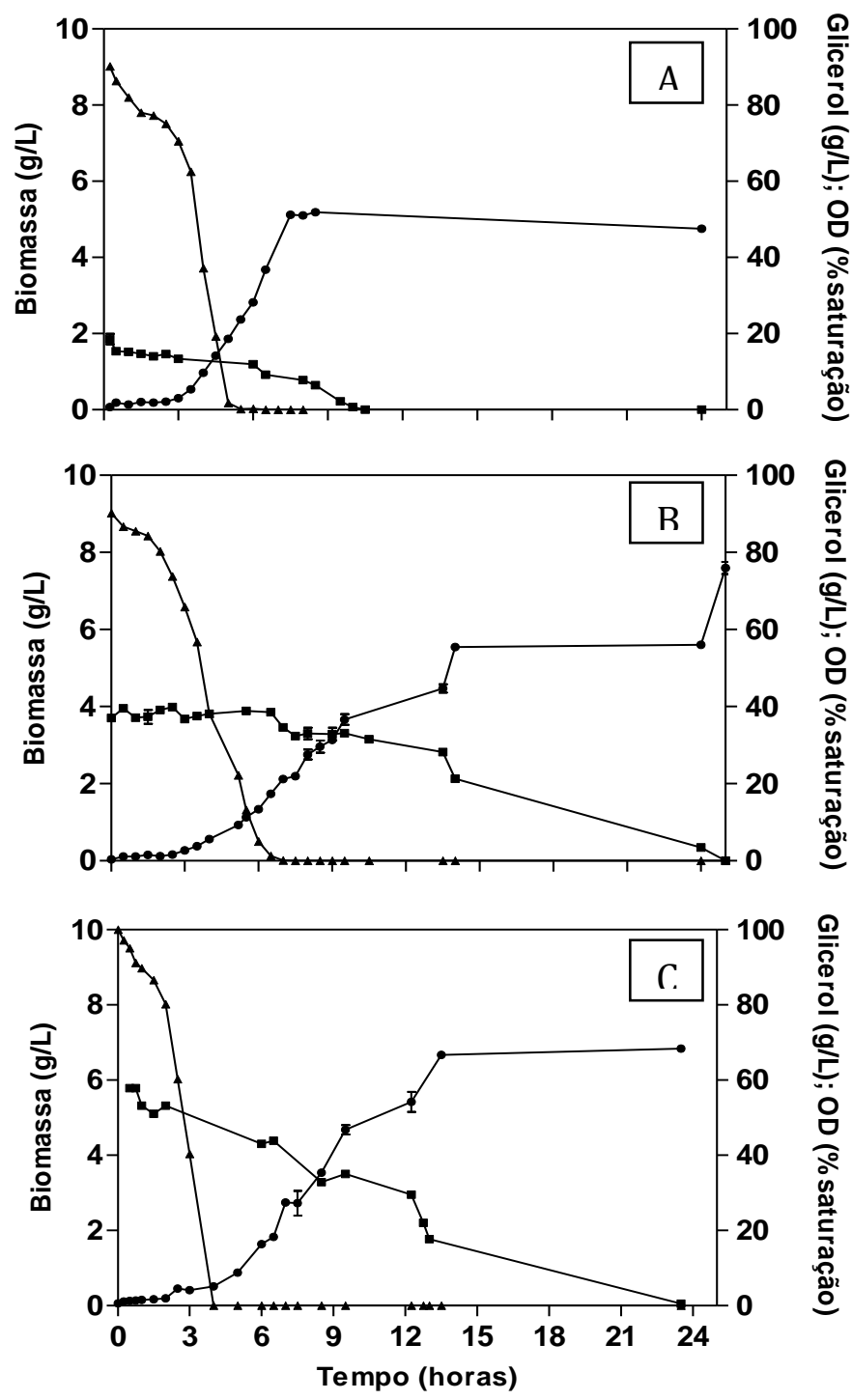

$\rightarrow$ Biomassa $\rightarrow$ Glicerol $\rightarrow$ Oxigênio Dissolvido

Figura 1 - Perfis cinéticos de crescimento celular, de consumo de glicerol e percentual de oxigênio dissolvido em função do tempo, em cultivos de Klebsiella oxytoca ATCC8724 em meios contendo

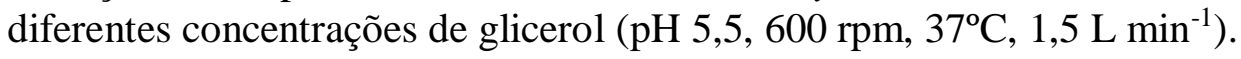

$$
\text { (A) } 20 \mathrm{~g} / \mathrm{L} \text {; (B) } 40 \mathrm{~g} / \mathrm{L} \text {; (C) } 60 \mathrm{~g} / \mathrm{L}
$$


Como pode ser observado na Tabela 1, máxima velocidade específica de crescimento $\left(\mu_{\mathrm{x}, \max }\right)$ foi estimada em cultivo com $40 \mathrm{~g} / \mathrm{L}$ de glicerol, de $0,90 \mathrm{~h}^{-1}$ e valor médio de $0,8 \mathrm{~h}^{-1}$ quando utilizados 20 ou $60 \mathrm{~g} / \mathrm{L}$ de glicerol. Estudos anteriores, realizados em frascos sob agitação, $\mu_{\mathrm{x}, \max }$ de cerca de $0,7 \mathrm{~h}^{-1}$ foi estimado com o uso de 20,40 e $60 \mathrm{~g} / \mathrm{L}$ de glicerol e, em concentrações superiores, 80 e $100 \mathrm{~g} / \mathrm{L}$, em torno de $0,5 \mathrm{~h}^{-1}$, indicando, nestes últimos cultivos, o efeito de inibição pelo substrato (Romio et.al., 2013b).

Tabela 1 - Resultados gerais dos cultivos de Klebsiella oxytoca ATCC8724 em biorreator de bancada, utilizando diferentes concentrações iniciais de glicerol $\left(\mathrm{pH} 5,5,600 \mathrm{rpm}, 37^{\circ} \mathrm{C}, 1,5 \mathrm{~L}\right.$ $\left.\min ^{-1}\right)$.

\begin{tabular}{|c|c|c|c|c|c|c|c|c|c|c|}
\hline $\begin{array}{c}\mathrm{S}_{0} \\
(\mathrm{~g} / \mathrm{L})\end{array}$ & th) & $\begin{array}{c}X_{f} \\
(g / L)\end{array}$ & $\begin{array}{c}\mu_{x \max } \\
\left(\mathrm{h}^{-1}\right)\end{array}$ & $\begin{array}{l}Y_{X / S} \\
(g / g)\end{array}$ & $\begin{array}{l}\text { Butanodiol } \\
\text { (g/L) }\end{array}$ & $\begin{array}{c}Y_{P / S} \\
\text { but } \\
(g / g)\end{array}$ & $\begin{array}{c}\rho \\
\text { but } \\
(\%)\end{array}$ & $\begin{array}{l}\text { Etanol } \\
(\mathrm{g} / \mathrm{L})\end{array}$ & $\begin{array}{l}Y_{P / S} \text { et } \\
(g / g)\end{array}$ & $\begin{array}{c}\rho \\
\text { et } \\
(\%)\end{array}$ \\
\hline $20(18,5)$ & 10 & 5,3 & 0,82 & 0,27 & 4,0 & 0,21 & 43 & 2,2 & 0,11 & 22 \\
\hline $40(37,0)$ & 25 & 7,4 & 0,90 & 0,20 & 9,2 & 0,25 & 51 & 2,9 & 0,08 & 15 \\
\hline $60(57,9)$ & 24 & 6,8 & 0,80 & 0,12 & 17,3 & 0,30 & 61 & 4,9 & 0,09 & 17 \\
\hline
\end{tabular}

Com relação à conversão de substrato em biomassa celular $\left(\mathrm{Y}_{\mathrm{X} / \mathrm{S}}\right)$, um comportamento decrescente em relação às concentrações de glicerol foi verificado, com maior eficiência em termos de conversão em concentrações mais baixas. Quando as condições para o crescimento se tornaram menos favoráveis, pela limitação de oxigênio, o glicerol ainda presente no meio passou a ser convertido em produtos do catabolismo, como o butanodiol, a fim de reoxidar a coenzima NADH. Com o aumento da concentração inicial de glicerol, a disponibilidade de substrato é maior quando há limitação de oxigênio e, como consequência, foi observado um incremento em termos de produção de butanodiol. Nestas condições, valores próximos a $17 \mathrm{~g} / \mathrm{L}$ de butanodiol e $5 \mathrm{~g} / \mathrm{L}$ de etanol foram estimados com $60 \mathrm{~g} / \mathrm{L}$ de substrato, representando um rendimento em torno de 61 e $17 \%$, respectivamente (Tabela 1). Nas condições testadas, baixo rendimento em termos de etanol foi devido ao fato de esta via metabólica ser menos favorecida para esse microrganismo. Silveira et al. (1998) relatam a obtenção de $74 \%$ de rendimento em 2,3butanodiol utilizando $60 \mathrm{~g} / \mathrm{L}$ de sacarose em cultivos batelada com o mesmo microrganismo e rendimentos de até $90 \%$ em cultivos em batelada alimentada.

O presente trabalho demonstrou a viabilidade do uso de glicerol como fonte de carbono para $K$. oxytoca com o fim de produção de 2,3-butanodiol. Comparando-se glicerol e glicose, determinou-se maior produção de butanodiol em meio formulado com glicerol, com o mesmo comportamento sendo observado com a produção de etanol (Romio et.al., 2013a). 


\section{CONCLUSÕES}

Os resultados deste trabalho mostraram que, a exemplo do que ocorre com substratos açucarados, o metabolismo de glicerol por $K$. oxytoca é dependente da disponibilidade ou limitação de oxigênio dissolvido. Foi observado que concentrações de glicerol de até $60 \mathrm{~g} / \mathrm{L}$ proporcionaram a obtenção de velocidades específicas de crescimento semelhantes, não se constatando a ocorrência de inibição por substrato. Quanto maior foi a quantidade de substrato disponível após a limitação de oxigênio, maior rendimento de butanodiol e etanol foi obtido, possibilitando uma maior conversão de substrato em produto.

Os dados indicam que o glicerol pode vir a ser um substrato tecnicamente e economicamente mais interessante que carboidratos simples, como a glicose ou a sacarose, para a produção de 2,3-butanodiol em maior escala, tendo em vista sua grande disponibilidade e baixo valor como resíduo da produção de biodiesel.

\section{NOMENCLATURA}

$\rho$ - rendimento da formação do produto.

$\mathrm{S}_{0}$ - concentração inicial de glicerol.

$\mathrm{X}$ - concentração celular.

$\mathrm{Y}_{\mathrm{X} / \mathrm{S}}$ - fator de conversão de glicerol em células.

$\mathrm{Y}_{\mathrm{P} / \mathrm{S}}$ - fator de conversão de glicerol em produtos (butanodiol ou etanol).

$\mu_{\mathrm{x}, \max }$ - máxima velocidade específica de crescimento.

\section{AGRADECIMENTOS}

Agradecimentos à CAPES, PETROBRAS, FAPERGS e Universidade de Caxias do Sul pelo apoio na realização deste trabalho.

\section{REFERÊNCIAS}

AMARAL, P.F.F.; FERREIRA, T.F.; FONTES, G.C.; COELHO, M.A.Z. Glycerol valorization: new biotechnological routes. Food Bioprod. Process, v. 87, p.179-186, 2009.

CARRA, S. Estudo cinético de ácido lactobiônico e sorbitol por enzimas periplasmáticas de Zymomonas mobilis. Dissertação de mestrado. Universidade de Caxias do Sul, Programa de Pós-Graduação em Biotecnologia, Caxias do Sul, RS, 2012.

CONVERTI, A.; PEREGO, P. Use of carbon and energy balance in the study of the anaerobic metabolism of Enterobacter aerogenes at variable starting glucose concentrations. Appl. Microbiol. Biotechnol. v.59, p. 303-309, 2002. 
FLICKINGER, M.C. Current biological research in conversion of cellulosic carbohydrates into liquid fuels: how far have we come? Biotechnol. Bioeng. v.22, p. 27-48, 1980.

MENDES, F. Production of glycerol and 1,3-propanediol from renewable resources: study of new biocatalysts and process strategies. Dissertação de pós-doutorado. Escola Superior de Biotecnologia, Universidade Católica Portuguesa. Lisboa, Portugal, 2011.

PIRT, S.J.; CALLOW, D.S. Exocellular product formation by microorganisms in continuous culture. I - Production of 2,3-butanediol by Aerobacter aerogenes in a single stage process. $J$. Appl. Bacteriol., v. 21, p. 188-205, 1958.

ROMIO, T.; GIRARDI, V.; HARTMANN, C.; BARSÉ, B.; GRIGGIO, G. S.; TORRES, A. P. R.; SOUZA, M. P.; CARRA, S.; MALVESSI E.; BEAL, L.; SILVEIRA, M. M. Efeito do pH sobre o crescimento de Klebsiella oxytoca em meio contendo glicerol e glicose como fontes de carbono. XIX Simpósio Nacional de Bioprocessos, 2013a.

ROMIO, T.; HARTMANN, C.; VIAPLIANA, F.; CARRA, S.; BEAL, L.L.; TORRES, A. P. R.; SOUZA, M. P.; MALVESSI E.; SILVEIRA, M. M. Efeito da concentração de glicerol sobre a produção de butanodiol por Klebsiella oxytoca ATCC8724. $8^{\circ}$ Congresso Internacional de Bioenergia. 2013b.

ROSSI, D.M.; SOUZA, E.A.; FLORES, S.H. AYUB, M.A.Z. Conversion of residual glycerol from biodiesel synthesis into 1,3-propanediol by a new strain of Klebsiella pneumoniae. Renewable Energy SS, p. 404-409, 2013.

SILVA, G.P.; MACK, M.; CONTIERO, J. Glycerol: A promising and abundant carbon source for industrial microbiology. Biotechnol. Adv., v. 27, p. 30-39, 2009.

SILVEIRA, M.; MOLINA, M.A.B.; PRATA, A. M. R.; SCHMIDELL, W. Production of 2,3butanediol from sucrose by Klebsiella pneumoniae NRRL B199 in batch and fed-batch reactors. Arquivos de Biologia e Tecnologia. v.41(3), p. 329-334, 1998. 